\title{
TBC: A simple algorithm to rule out abnormalities in electrocardiograms of patients with pacemakers
}

Javier Higueras ${ }^{1}$, Carmen Olmos ${ }^{1}$, Julián Palacios-Rubio ${ }^{1,2}$, Juan Carlos Gómez-Polo ${ }^{1}$, Pedro Martínez-Losas ${ }^{1}$, Virginia Ruiz-Pizarro ${ }^{1}$, Ramón Bover ${ }^{1}$, Julián Pérez-Villacastín ${ }^{1,2}$

${ }^{1}$ Instituto Cardiovascular, Hospital Clínico San Carlos, Instituto de Investigación

Sanitaria del Hospital Clínico San Carlos (IdSSC), Madrid, Spain

${ }^{2}$ Unidad de Arritmias, Hospital Clínico San Carlos y CIBER-CV, Madrid, Spain

\begin{abstract}
Background: The aim of the study was to create a straightforward method to rule out abnormalities in electrocardiograms (ECGs) performed in patients with pacemakers.

Methods: The TBC method screens the ECG for any of the following findings: Tachycardia with pacing spikes, Bradycardia without spikes and Chaos with spikes unrelated to QRS-T complexes. T was considered to advise for patient assessment and $B$ and $C$ to require referral for urgent pacemaker evaluation. The diagnostic accuracy of the algorithm was validated using a cohort of 151 ECGs with normal and dysfunctional pacemakers. The effect of the algorithm was then evaluated for diagnostic skills and management of patients with pacemakers by non-cardiologists, comparing their diagnostic accuracy before and after teaching the algorithm.

Results: The TBC algorithm had a sensitivity of $86 \%$ and a specificity of $94 \%$ in diagnosing a malfunctioning pacemaker. The diagnostic skills and patient referral were significantly improved $(74.8 \%$ vs. $89.5 \%, p<0.001$; and $57.4 \%$ vs. $83 \%, p<0.001$ ).

Conclusions: $T B C$ is an easy to remember and apply method to rule out severe abnormalities in ECGs of patients with pacemakers. TBC algorithm has a very good diagnostic capability and is easily applied by non-expert physicians with good results. (Cardiol J 2020; 27, 2: 136-141)
\end{abstract}

Key words (MeSH; *: major): pacemaker, artificial*; pacemaker, artificial/education; pacemaker, artificial/therapy; electrocardiography*; electrocardiography/education

\section{Introduction}

Interpreting the electrocardiogram (ECG) in patients with a pacemaker (PM) poses a challenge for most physicians outside the field of cardiology. The number of patients with a PM is rising worldwide [1,2], which increases the likelihood that a physician who is not specialist in cardiology will face an ECG of a patient with a PM during daily practice. There is a large variety of devices and programming modes, making the recognition of normal patterns even harder. Apart from this, there is a tightening pressure in healthcare that does allow enough time in the clinic to request expert advice or browse literature, the latter usually being highly technical and difficult to understand. Some ECG recording devices have an automated interpretation feature, but this tool might be misleading professionals if the suggested diagnosis is wrong [3]. Another difficulty upon interpreting these ECGs, other than recognizing the very problem, is to assess its severity. It has recently been

Address for correspondence: Javier Higueras, MD, PhD, Instituto Cardiovascular, Hospital Clínico San Carlos, Instituto de Investigación Sanitaria del Hospital Clínico San Carlos (IdSSC), C/Profesor Martín Lagos, s/n, 28040 Madrid, Spain, tel: +34 9133030 00, fax: +34 9133031 82, e-mail: javierhnb@yahoo.es

Received: 6.07.2017 Accepted: 31.03.2018 


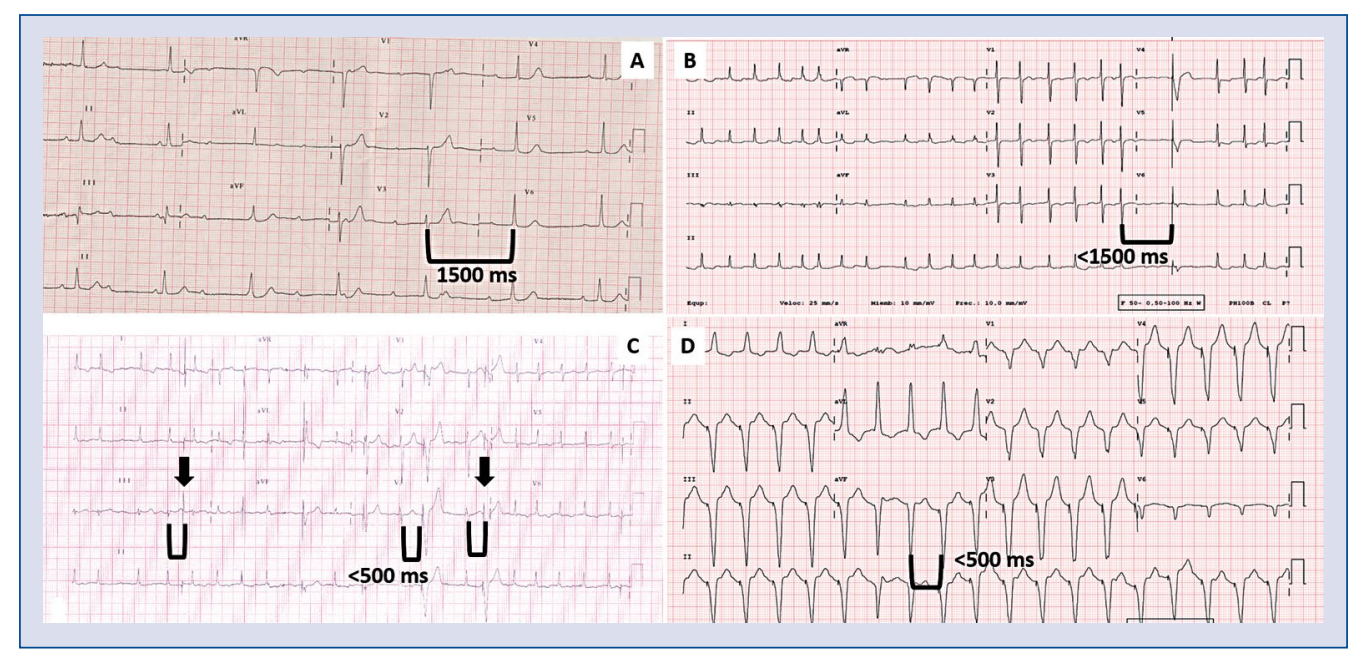

Figure 1. A. A dysfunctional pacemaker electrocardiogram (ECG) (depleted battery) that meets Bradycardia criterion, because there are no QRSs (with or without spikes) during $1500 \mathrm{~ms}$ from the onset of the previous QRS; B. A shorter bradycardia that does not meet Bradycardia criterion; C. A dysfunctional pacemaker (failure to sense). This ECG meets two criteria: 1) Chaos, because there are spikes within the QRS-T complex (black arrows) and Tachycardia because there are pacing artifacts at less than $500 \mathrm{~ms}$ from the onset of the previous QRS; D. This ECG corresponds to a dual chamber pacemaker following an atrial flutter. It shows pacing artifacts at less than $500 \mathrm{~ms}$ from the onset of the previous QRS, meeting the Tachycardia criterion.

published that many potentially lethal issues are both underdiagnosed and underestimated by those who diagnose them, including ECGs with PM [4]. Severe diagnoses are often missed due to a lack of expertise in the characteristics of the tracings created by these devices either functioning normally or with some kind of malfunction [4].

With that in mind, created herein is a straightforward method, TBC algorithm, which does not require specialized knowledge to detect most issues with these patients: PM dysfunction or arrhythmia warranting parameter reprogramming or patient assessment (i.e. cardioversion or anticoagulation).

The aims of this work were: 1) to validate TBC algorithm in a sample of ECGs showing PM normal function and dysfunction; and 2) to evaluate if teaching the algorithm to a group of noncardiologist physicians improves their diagnostic accuracy in PM-related pathology.

\section{Methods}

\section{TBC algorithm}

The $\mathrm{TBC}$ algorithm provides a structured approach to the ECG of a patient with a PM. It considers that there is no rhythm- or PM-related issue if it does not meet any of the following:

- Tachycardia with spikes (T): pacing artifacts ("spikes") at less than $500 \mathrm{~ms}$ (i.e. $120 \mathrm{bpm}$ or $2.5 \mathrm{big}$ squares at $25 \mathrm{~mm} / \mathrm{s}$ sweep speed) from the onset of the previous QRS;

- Bradycardia without spikes (B): no QRSs during $1500 \mathrm{~ms}$ (i.e. $40 \mathrm{bpm}$, or 7-and-a-half big squares) from the onset of the previous QRS; - Chaos (C): spikes unrelated to QRSs (i.e. spikes within the QRS-T complex or spikes not followed by QRS and at different distances from the following QRS).

The $\mathrm{T}$ criterion was considered to require a more thorough patient assessment and to consider elective referral to a specialist, since it is not usually related to a severe PM dysfunction but to an issue in programming (i.e. PM-mediated tachycardia). On the other hand, the $\mathrm{B}$ and $\mathrm{C}$ categories need urgent PM evaluation since they might indicate a severe malfunction. Figure 1 shows examples of the three criteria.

\section{Algorithm validation}

The algorithm's diagnostic accuracy was evaluated by applying it to ECGs from a series of patients admitted to the documented service with a malfunctioning PM, as well as to a set of published cases and reports, and to consecutive patients with normal functioning PM who had just undergone their routine device check-up. The gold standard for an ECG being diagnostic of PM malfunction was the assessment by an expert cardiologist. 
PM malfunctions that can only be diagnosed by device interrogation (vg. threshold rise, impedance drop) and are not by any means apparent in surface ECGs were excluded from this trial, for obvious reasons.

\section{Algorithm usefulness to improve the diagnostic yield and patient management by non-cardiologists}

The aim of this study was to test the usefulness of TBC algorithm to diagnose PM-dysfunction by non-cardiologists. Attendees of a basic electrocardiography course were given 5 randomly chosen ECGs before and after a short 15-min lecture on TBC algorithm. Two questions were asked to every participant for each ECG: "Is there a problem with this patient and/ /or the PM?" and "Do you think that this patient needs assessment by a specialist? (Yes, urgent / /Yes, elective / No, routine follow-up)". The only clinical information provided was "The patient visited the clinic for minor symptoms", and the right answers were not disclosed until completion of the second test. In order to avoid any potential bias, the authors of this work did not teach any lecture except "TBC algorithm". The lectures about traditional PM electrocardiography were taught by electrophysiologists. Attendee assessment of ECGs was compared to the evaluation performed by a cardiologist expert in electrocardiography.

\section{Statistical analysis}

Categorical variables are expressed as frequency and percentage, and were compared with the $\chi^{2}$ test and Fisher exact test when appropriate. Continuous variables are reported as a mean value and standard deviation (SD), and were compared by a two-tailed Student t-test.

Performance of TBC algorithm in a sample of 151 ECGs of normal functioning and dysfunctioning PM was assessed by analyzing discrimination (receiver operating characteristic [ROC] curve). Sensitivity, specificity, positive and negative predictive values, with $95 \%$ confidence intervals (CI) are shown.

To assess TBC algorithm usefulness in improving diagnostic skills of non-cardiologist physicians, right answers were compared for each participant before and after teaching the algorithm, using a relative symmetry test and the McNemar-Bowker symmetry test for variables over two categories.

All tests were two-sided and differences were considered statistically significant at $\mathrm{p}$-values
Table 1. The 47 TBC algorithm criteria detected in 44 electrocardiograms of pacemakers deemed malfunctional.

\begin{tabular}{lc}
\hline Matching criterion & N (\%) \\
\hline Tachycardia & $9(19.14 \%)$ \\
Bradycardia & $13(27.65 \%)$ \\
Chaos (see text) & $25(53.19 \%)$ \\
\hline
\end{tabular}

Table 2. Type of electrocardiograms of the 100 patients with normally functioning pacemakers used in the validation phase.

\begin{tabular}{lc}
\hline Tracing type & N (\%) \\
\hline $\begin{array}{l}\text { Sinus rhythm and intrinsic } \\
\text { ventricular conduction }\end{array}$ & $20(20 \%)$ \\
$\begin{array}{l}\text { Sinus rhythm and ventricular } \\
\text { pacing }\end{array}$ & $32(32 \%)$ \\
$\begin{array}{l}\text { Atrial fibrillation and intrinsic } \\
\text { ventricular conduction }\end{array}$ & $3(3 \%)$ \\
$\begin{array}{l}\text { Atrial fibrillation and ventricular } \\
\text { pacing }\end{array}$ & $29(29 \%)$ \\
$\begin{array}{l}\text { Dual chamber pacing } \\
\text { Atrial pacing and intrinsic } \\
\text { ventricular conduction }\end{array}$ & $10(10 \%)$ \\
\hline
\end{tabular}

$<0.05$. Statistical analysis was performed with Stata V.12.0 (StataCorp, College Station, Texas, USA).

\section{Results}

\section{TBC algorithm validation}

Of 51 malfunctioning PM ECGs assessed, TBC algorithm indicated an abnormality in 44 . The cases undiagnosed by TBC algorithm included a depleted PM with an acceptable escape rate, upper-rate behavior, 3 cases with atrial undersensing, 3 losses of atrial capture and 1 auto-threshold algorithm. Table 1 shows the distribution of criteria detected by TBC. Among the 44 ECGs detected as pathological, in 3 cases two criteria were met.

In addition, the ECGs from 100 consecutive patients with a normally functioning PM were assessed. 6 ECGs were mistaken as pathological by TBC algorithm: 2 cases with intermittent atrial pacing and a low-voltage p-wave that could be mistaken as a spike without QRS, an atrial premature beat tracked by ventricular lead, undersensing of a ventricular premature beat, pseudofusions in the presence of right bundle branch block, and a case with a lower rate limit under $40 \mathrm{bpm}$. Table 2 shows the types of tracings included. 
Table 3. Baseline diagnostic skills of pacemaker's electrocardiograms (ECG) by non-cardiologist physicians.

\begin{tabular}{|c|c|c|c|c|c|c|}
\hline \multirow[t]{4}{*}{ ECG } & \multirow{2}{*}{\multicolumn{5}{|c|}{$\begin{array}{l}\text { Question: Is there an issue with this patient or pacemaker? } \\
\text { Right answers }\end{array}$}} & \multirow[t]{4}{*}{$\mathbf{P}^{*}$} \\
\hline & & & & & & \\
\hline & \multirow[t]{2}{*}{ Expert } & \multirow{2}{*}{$\begin{array}{l}\text { Overall } \\
\text { sample } \\
(n=61)\end{array}$} & \multicolumn{3}{|c|}{ Results by medical specialty } & \\
\hline & & & $\begin{array}{c}\text { General } \\
\text { practitioners } \\
(\mathbf{n}=12)\end{array}$ & $\begin{array}{l}\text { Emergency } \\
\text { physicians } \\
\text { (n=7) }\end{array}$ & $\begin{array}{c}\text { Medical } \\
\text { specialties } \\
\text { fellows } \\
\text { (n = 42) }\end{array}$ & \\
\hline Depleted PM & Yes & $57(93.44 \%)$ & $10(83.33 \%)$ & $7(100 \%)$ & $40(95.24 \%)$ & 0.257 \\
\hline Atrial flutter tracked by PM & Yes & $19(31.15 \%)$ & $3(25.00 \%)$ & $2(28.57 \%)$ & $14(33.33 \%)$ & 0.849 \\
\hline $\begin{array}{l}\text { Sinus rhythm with intrinsic } \\
\text { conduction }\end{array}$ & No & $53(86.89 \%)$ & $11(91.67 \%)$ & $5(71.43 \%)$ & $37(88.10 \%)$ & 0.414 \\
\hline Failure to capture & Yes & $59(96.72 \%)$ & $11(91.67 \%)$ & $7(100 \%)$ & $41(97.62 \%)$ & 0.519 \\
\hline $\begin{array}{l}\text { Atrial fibrillation with } \\
\text { intrinsic conduction }\end{array}$ & No & $40(65.57 \%)$ & $8(66.67 \%)$ & $5(71.43 \%)$ & $27(64.29 \%)$ & 0.931 \\
\hline
\end{tabular}

*P-value for comparison of distribution of physicians among medical specialties; PM — pacemaker

The diagnostic accuracy of TBC algorithm for diagnosing a malfunctioning PM in the present sample was high, with $86.3 \%$ sensitivity (95\% CI 74.3-93.2\%), 94.2\% specificity (95\% CI $87.9-97.3 \%), 88 \%$ positive predictive value for PM malfunction (95\% CI 76.2-94.4\%), and 93.3\% negative predictive value (95\% CI 86.8-95.0\%). The overall performance had a positive likelihood ratio of 14.8 , and an area under the ROC curve of 0.90 (95\% CI 0.84-0.94).

\section{Usefulness of the TBC algorithm to improve physician diagnosis and management of ECGs}

Sixty one non-cardiologist physicians participated, of which 46 (75\%) were women. Mean age was 31.5 (9.6) years old. They had been working as physicians for 6.1 (8.6) years. There were $12(20 \%)$ general practitioners, 7 (11\%) emergency physicians and $42(69 \%)$ medical specialties fellows.

After a basic electrocardiography course, that contained a classic review of PM malfunction, but before presentation of TBC algorithm, they properly diagnosed an average of $3.7(74 \%)$ ECGs. A latent confusion was observed, considering that normal ECGs in patients with PMs were pathological: for instance, the ECG of a patient with atrial fibrillation and ventricular demand pacing was wrongly deemed malfunctional by 21 (34\%) physicians. The recommended course of action for each patient according to the ECG shown was evaluated: in 2.87 (57.4\%) cases, appropriate management was suggested. The distribution of correct answers by ECG and physician background is provided in Table 3 .

After teaching TBC algorithm, the number of correct answers in the diagnosis of pathological ECGs rose significantly (3.7 vs. $4.5 ; \mathrm{p}<0.001$ ), as well as the number of physicians properly answering all 5 ECGs (9 vs. 36). The distribution of correct answers after showing $\mathrm{TBC}$ algorithm is provided in Table 4.

Regarding patient referral for PM evaluation, teaching TBC algorithm had significantly improved the appropriate referral of patients for cardiology assessment ( $57.4 \%$ vs. $83 \%$; p < 0.001). Before explaining the algorithm, only 2 physicians managed appropriately all 5 ECGs, while 6 failed every tracing; after TBC was explained, 27 physicians referred appropriately all patients, and only 1 failed every ECG (Table 5).

\section{Discussion}

The present work shows that TBC algorithm helps non-cardiologist physicians to diagnose and manage patients appropriately with a PM, according to their surface ECG. It has been published elsewhere that internship and residency do not grant sufficient skills in electrocardiography [5], and physicians overall have a shallow knowledge on this matter [4, 6, 7]. Several studies have shown that diagnostic skills improve by up to $15 \%$ after teaching courses both in-person and on-line $[8,9]$. There is a current trend in medical teaching based in creative teaching, innovation, mnemonic rules and 
Table 4. Management suggested by physicians according to their interpretation of the pacemakers electrocardiograms (ECG) before learning the TBC algorithm.

\begin{tabular}{|c|c|c|c|c|c|c|}
\hline \multirow[t]{4}{*}{ ECG } & \multirow{2}{*}{\multicolumn{5}{|c|}{$\begin{array}{l}\text { Question: Would you refer this patient for further evaluation? } \\
\qquad \text { Right answers }\end{array}$}} & \multirow[t]{4}{*}{$P^{*}$} \\
\hline & & & & & & \\
\hline & \multirow[t]{2}{*}{ Expert } & \multirow{2}{*}{$\begin{array}{l}\text { Overall } \\
\text { sample } \\
(n=61)\end{array}$} & \multicolumn{3}{|c|}{ Results by medical specialty } & \\
\hline & & & $\begin{array}{l}\text { General } \\
\text { practitioners } \\
(\mathbf{n}=12)\end{array}$ & $\begin{array}{l}\text { Emergency } \\
\text { physicians } \\
\text { (n=7) }\end{array}$ & $\begin{array}{l}\text { Medical } \\
\text { specialties fel- } \\
\text { lows } \\
(n=42)\end{array}$ & \\
\hline Depleted PM & Yes & $53(86.89 \%)$ & $9(75.00 \%)$ & $7(100 \%)$ & $37(88.10 \%)$ & 0.273 \\
\hline Atrial flutter tracked by PM & Yes & $8(13.11 \%)$ & $2(16.67 \%)$ & $1(14.29 \%)$ & $5(11.90 \%)$ & 0.907 \\
\hline $\begin{array}{l}\text { Sinus rhythm with intrinsic } \\
\text { conduction }\end{array}$ & No & $51(83.61 \%)$ & $11(91.67 \%)$ & $5(71.43 \%)$ & $35(83.33 \%)$ & 0.515 \\
\hline Failure to capture & Yes & $28(45.90 \%)$ & $3(25.00 \%)$ & $3(42.86 \%)$ & $22(52.38 \%)$ & 0.241 \\
\hline $\begin{array}{l}\text { Atrial fibrillation with } \\
\text { intrinsic conduction }\end{array}$ & No & $35(57.38 \%)$ & $7(58.33 \%)$ & $4(57.14 \%)$ & $24(57.14 \%)$ & 0.997 \\
\hline
\end{tabular}

*P-value for comparison of distribution of physicians among medical specialties; PM — pacemaker

Table 5. Comparison of diagnostic yield and patient management, before and after learning TBC algorithm.

\begin{tabular}{|c|c|c|c|c|c|c|}
\hline \multirow[t]{2}{*}{ Electrocardiogram } & \multicolumn{3}{|c|}{$\begin{array}{l}\text { Is there any issue with this } \\
\text { patient or pacemaker? } \\
\text { Correct answers }\end{array}$} & \multicolumn{3}{|c|}{$\begin{array}{l}\text { Would you refer this patient } \\
\text { for further evaluation? } \\
\text { Correct answers }\end{array}$} \\
\hline & Before TBC & After TBC & $\mathbf{P}$ & Before TBC & After TBC & $\mathbf{P}$ \\
\hline Depleted pacemaker & $57(93.44 \%)$ & $58(95.08 \%)$ & 0.007 & $53(86.89 \%)$ & $56(91.8 \%)$ & 0.125 \\
\hline $\begin{array}{l}\text { Atrial flutter tracked } \\
\text { by pacemaker }\end{array}$ & $19(31.15 \%)$ & $56(91.8 \%)$ & 0.015 & $8(13.11 \%)$ & $51(83.61 \%)$ & $<0.001$ \\
\hline $\begin{array}{l}\text { Sinus rhythm with } \\
\text { intrinsic conduction }\end{array}$ & $53(86.89 \%)$ & $57(93.44 \%)$ & 0.135 & $51(83.61 \%)$ & $53(86.89 \%)$ & 0.070 \\
\hline Failure to capture & $59(96.72 \%)$ & $59(96.72 \%)$ & 0.079 & $28(45.9 \%)$ & $53(86.89 \%)$ & $<0.001$ \\
\hline $\begin{array}{l}\text { Atrial fibrillation with } \\
\text { intrinsic conduction }\end{array}$ & $40(65.57 \%)$ & $43(70.49 \%)$ & 0.649 & $35(57.38 \%)$ & $40(65.57 \%)$ & 0.004 \\
\hline
\end{tabular}

new technologies [9-11]. Therefore, it is valuable to have a straightforward algorithm to rule out pathology apparent in the ECG of patients having a PM.

TBC algorithm provides a structured, simple approach, which requires no specialized knowledge and can be taught in some minutes. It helps to detect most severe PM-related disorders that are apparent on a surface ECG. In the present validation sample diagnostic yield of TBC algorithm was very good, with $86 \%$ sensitivity, $94 \%$ specificity and area under the ROC curve 0.90 .

Applying TBC algorithm after a short training, non-cardiologists were able to detect most PM-related disorders apparent on an ECG. The physicians participating in the present sample showed higher-than-average baseline skills in ECG interpretation [4], most likely due to selection bias since they attended an electrocar- diography course. Even though this might have decreased the usefulness of the algorithm, it still showed a significant improvement, both in diagnostic skills and appropriate management decisions. TBC algorithm proved useful in improving risk stratification in patients with a nondysfunctional ECG to be kept under ordinary follow-up, ECGs showing alterations warranting a more thorough assessment, and ECGs with potentially severe, urgent disorders.

\section{Limitations of the study}

This work has several limitations. Firstly, it is known that any kind of intervention in the form of instruction is likely to improve the performance in ECG reading; thus, repeating the initial lecture on ECG interpretation might have led to similar results. 
Secondly, the algorithm is usually unable to diagnose most of the issues caused by an atrial lead dysfunction, especially if these are not associated with disorders in ventricular pacing. This was considered while designing the algorithm, but considering that increasing the number of variables would make it more complex, and therefore harder to apply, additionally troubles caused by an atrial lead dysfunction are seldom severe. Regarding dual-chamber pacemakers, it should be stressed that, for $\mathrm{C}$ criterion to be met, spikes should not be immediately followed by a QRS and they must be at different distances from the following QRS. This discriminates normally functioning dual-chamber pacemakers, where atrial spikes are not adjacent to a QRS but they are kept at a constant distance to the following QRS.

V00 programming in an otherwise functional $\mathrm{PM}$, which is exceptional in outpatients but it could be seen in some circumstances in a hospital setting (i.e. operating room, magnetic resonance...), and could create apparent chaos and thus be mistakenly considered a malfunction by the algorithm. It could also be mistaken as malfunctional tracing showing advanced PM functions, such as ventricular pacing reduction or auto-threshold search, but those are rarely recorded in a 10-s ECG and they are usually impossible to be positively differentiated from a malfunctioning PM. The remaining severe, common PM-related disorders that can be diagnosed by the ECG are within the scope of the present algorithm.

Finally, regarding external validity of the test, ECGs used for this trial on non-cardiologists were manually chosen. To the best of then present knowledge, there was no standardized test to assess knowledge on ECGs, so ECGs were picked that were considered to feature common disorders seen in clinics.

\section{Conclusions}

TBC algorithm is an easy to remember and apply method to rule out severe abnormalities in ECGs of patients with PM. TBC has a very good diagnostic capability and is easily applied by nonexpert physicians with good result in correctly identifying PM malfunction.

\section{Acknowledgements}

The authors thank the entire cardiology team of Hospital Clínico San Carlos, with special grati- tude to the nurses of the cardiology and electrophysiology unit for their contribution. Without them, this work could not have been done.

\section{Conflict of interest: None declared}

\section{References}

1. Cano Pérez Ó, Pombo Jiménez M, Fidalgo Andrés ML, et al. Spanish Pacemaker Registry. 14th Official Report of the Spanish Society of Cardiology Working Group on Cardiac Pacing (2016). Rev Esp Cardiol (Engl Ed). 2017; 70(12): 1083-1097, doi: 10.1016/j.rec.2017.08.017, indexed in Pubmed: 28965962.

2. Raatikainen MJ, Arnar DO, Zeppenfeld K, et al. Statistics on the use of cardiac electronic devices and electrophysiological procedures in the European Society of Cardiology countries: 2014 report from the European Heart Rhythm Association. Europace. 2015; 17 Suppl 1: i1-75, doi: 10.1093/europace/euu300, indexed in Pubmed: 25616426.

3. Martínez-Losas P, Higueras J, Gómez-Polo JC, et al. The influence of computerized interpretation of an electrocardiogram reading. Am J Emerg Med. 2016; 34(10): 2031-2032, doi: 10.1016/j.ajem.2016.07.029, indexed in Pubmed: 27489186.

4. Gómez-Polo JC, Higueras Nafría J, Martínez-Losas P, et al. Poor knowledge of potentially lethal electrocardiographic patterns in asymptomatic patients among noncardiologist physicians, and underestimation of their seriousness. Rev Esp Cardiol (Engl Ed). 2017; 70(6): 507-508, doi: 10.1016/j.rec.2016.09.021, indexed in Pubmed: 28277265.

5. Pinkerton RE, Francis CK, Ljungquist KA, et al. Electrocardiographic training in primary care residency programs. JAMA. 1981; 246(2): 148-150, indexed in Pubmed: 7241746.

6. Woolley D, Henck M, Luck J. Comparison of electrocardiogram interpretations by family physicians, a computer, and a cardiology service. J Fam Pract. 1992; 34(4): 428-432, indexed in Pubmed: 1556536.

7. Goy JJ, Schlaepfer J, Stauffer JC. Competency in interpretation of 12-lead electrocardiogram among Swiss doctors. Swiss Med Wkly. 2013; 143: w13806, doi: 10.4414/smw.2013.13806, indexed in Pubmed: 23740141.

8. Mahler SA, Wolcott CJ, Swoboda TK, et al. Techniques for teaching electrocardiogram interpretation: self-directed learning is less effective than a workshop or lecture. Med Educ. 2011; 45(4): 347-353, doi: 10.1111/j.1365-2923.2010.03891.x, indexed in Pubmed: 21401682 .

9. Rankin J, Brown V. Creative teaching method as a learning strategy for student midwives: A qualitative study. Nurse Educ Today. 2016; 38: 93-100, doi: 10.1016/j.nedt.2015.12.009, indexed in Pubmed: 26775032.

10. Chew KS, Durning SJ, van Merriënboer JJg. Teaching metacognition in clinical decision-making using a novel mnemonic checklist: an exploratory study. Singapore Med J. 2016; 57(12): 694-700, doi: 10.11622/smedj.2016015, indexed in Pubmed: 26778635.

11. Breen CJ, Bond R, Finlay D. An evaluation of eye tracking technology in the assessment of 12 lead electrocardiography interpretation. J Electrocardiol. 2014; 47(6): 922-929, doi: 10.1016/j.jelectrocard.2014.08.008, indexed in Pubmed: 25200901. 